\title{
Study on Quantitative Correlations between the Ageing Condition of Transformer Cellulose Insulation and the Large Time Constant Obtained from the Extended Debye Model
}

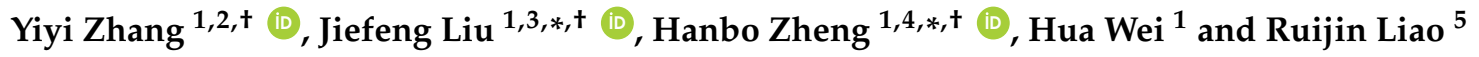 \\ 1 Guangxi Key Laboratory of Power System Optimization and Energy Technology, Guangxi University, \\ Nanning 530004, China; yiyizhang@gxu.edu.cn (Y.Z); weihua@gxu.edu.cn (H.W.) \\ 2 National Demonstration Center for Experimental Electrical Engineering Education, Guangxi University, \\ Nanning 530004, China \\ 3 Shijiazhuang Power Supply Branch of State Grid Electric Power Company, Shijiazhuang 050000, China \\ 4 State Grid Henan Electric Power Research Institute, Zhengzhou 450052, China \\ 5 State Key Laboratory of Power Transmission Equipment \& System Security and New Technology, \\ Chongqing University, Chongqing 400044, China; rjliao@cqu.edu.cn \\ * Correspondence: liujiefeng9999@163.com (J.L.); hanbozheng@163.com (H.Z.); \\ Tel.: +86-0771-323-2837 (J.L.); +86-159-0399-0863 (H.Z.) \\ + These authors contributed equally to this work.
}

Received: 19 October 2017; Accepted: 7 November 2017; Published: 11 November 2017

\begin{abstract}
Polarization-depolarization current (PDC) measurements are now being used as a diagnosis tool to predict the ageing condition of transformer oil-paper insulation. Unfortunately, it is somewhat difficult to obtain the ageing condition of transformer cellulose insulation using the PDC technique due to the variation in transformer insulation geometry. In this literature, to quantify the ageing condition of transformer cellulose insulation using the PDC technique, we firstly designed a series of experiments under controlled laboratory conditions, and then obtained the branch parameters of an extended Debye model using the technique of curve fitting the PDC data. Finally, the ageing effect and water effect on the parameters of large time constant branches were systematically investigated. In the present paper, it is observed that there is a good exponential correlation between large time constants and degree of polymerization (DP). Therefore, the authors believe that the large time constants may be regard as a sensitive ageing indicator and the nice correlations might be utilized for the quantitative assessment of ageing condition in transformer cellulose insulation in the future due to the geometry independence of large time constants. In addition, it is found that the water in cellulose pressboards has a predominant effect on large time constants.
\end{abstract}

Keywords: polarization-depolarization current; transformer cellulose insulation; ageing effect; water effect; quantitative correlation; large time constant

\section{Introduction}

Transformers, widely in the electric power transmission and transformation area, are regarded as one of the most important pieces of equipment [1,2]. Unfortunately, during their long operation period, the ageing of transformer insulation inevitably occurs due to the complicated operating conditions [3-5]. Once the power transformer ages, its insulation compounds obviously degrade, which increases risk of dielectric failure. The degradation/ageing of transformer insulation compounds is regarded as one of the major factors of outages in large transformers. It is believed that a suddenly occurring insulation failure in a transformer can be traced back to its insulation degradation/ageing. It is believed that 
many power transformers now in use are close to the end of their service life. Replacing them with new ones, based only on their insulation ageing, is clearly unadvisable. This is due to that some of these transformers may still be in good operation conditions and could be serviced to extend their in use duration. Therefore, preventing insulation failures and keeping power transformers in better operating conditions is an important topic for utility professionals.

Nowadays, a great number of studies in relation to fault diagnosis, life estimation, and reliability analysis techniques for transformer insulation have been widely reported [6-10]. The authors in [6] reviewed the diagnostic measurements for power transformers using the techniques of partial discharge (PD), frequency response analysis (FRA), dissolved gas analysis (DGA) and dielectric response measurement (DRM). It has been observed that these diagnostic measurement techniques have certain limitations, but with some obvious improvements it is shown that it is possible to determine the internal condition of power transformers with these diagnostic techniques. In [7] the authors reported a comprehensive review in terms of the analysis and discussion of the effect of loads and other key factors on oil-transformer ageing. In addition, each factor was analysed in detail and useful comparative tables were also created. This contributed significantly to insulation diagnosis and life estimation in transformers. An induced voltages ratio-based algorithm for fault detection, faulted phases and winding identification of a three-winding power transformer in an electrical power system was proposed in [8]. The intelligent algorithm presented in the paper can not only detect an internal fault, but also identify the faulted phase and winding of a three-winding power transformer. This novel algorithm may be applied to the insulation fault diagnosis on oil-filled transformers with different voltage levels. Wang et al. [9] presented a new concept about overload capability assessment of transformers. It is found that, compared with the previous studies that without regard to the overloading probability, the assessment results obtained in the work are much more reliable. This new idea can contribute to the overload capability assessment of oil-filled transformers. Prasojo et al. [10] reported the expected life estimation of transformer cellulose insulation using ANFIS based upon the oil characteristics and dissolved gases analysis. The proposed ANFIS model has $89.07 \%$ training accuracy and $85.75 \%$ testing accuracy and provides a helpful assistance for experts in transformer condition assessment.

As for the techniques reported in [6-10], the DRM techniques are more suitable for the insulation assessment/diagnosis on field transformers due to the abundant information obtained from transformer insulation. It is generally accepted that the understanding and interpretation of the correlations between the PD signals and transformer insulation ageing is rather more difficult. Moreover, onsite/online PD measurements are often affected by the high noise levels in the field. As for the FRA technique, we believe that it is a helpful tool for indicating electrical or mechanical damages to transformer windings. However, there are now no clear correlations between FRA data and transformer insulation ageing. The DGA technique, presently, is generally used for transformer insulation fault diagnosis/assessment because of the convenience for using it in the field. Using artificial intelligence or machine learning techniques (fuzzy logic model, neural networks, wavelet-based algorithms, adaptive neuro-fuzzy inference system, grey clustering analysis, etc.), power utilities can perform the fault diagnosis/ageing assessment on transformer insulation. It has been shown that the DGA technique can not only effectively determine the transformer fault types but also estimate qualitatively the degradation/ageing conditions of transformer insulation. Unfortunately, this general methodology cannot perform quantitative insulation evaluation.

At present, many publications have generally reported that the operating life of a transformer is predominantly determined by the operating life of its cellulose insulation [11,12]. Until now, taking several paper/pressboard specimens to obtain the degree of polymerization (DP) value is the most effective technique for residual life evaluation in transformer insulation, nevertheless, the sampling technique is both impractical and destructive [12,13]. It is generally believed that the oil specimen analysis (OSA) technique can be commonly utilized for the prediction of ageing condition in transformer cellulose insulation due to the undamaged oil sampling [7]. However, the OSA technique only provides quite inadequate information relevant to the ageing condition of transformer cellulose 
insulation $[2,12,13]$. Moreover, the furan measurement technique is a practical method for quantitatively assessing transformer cellulose insulation ageing [11]. Unfortunately, the furan measurement is severely influenced by thermosiphoning and furan distribution between oil and cellulose. Nowadays, the hot-spot temperature on transformer windings is also used for assessing the ageing condition of transformer cellulose insulation, although it is observed that there is a correlation between cellulose ageing and hot-spot temperature, this relations have not been quantified yet. Under the present economic conditions, it is an important issue for power utilities to quantitatively acquire the ageing condition of transformer cellulose insulation using appropriate diagnostic techniques.

Over the last few years, the demand to non-destructively and reliably obtain the transformer insulation condition has greatly accelerated the improvement of DRM techniques, such as Return Voltage Measurement (RVM) [14,15], Polarization and Depolarization Current (PDC) [16-18], and Frequency Domain Spectroscopy (FDS) [19-21]. The transformer insulation system contains insulation oil and cellulose material, and its dielectric properties are strongly affected by the test temperature, ageing and moisture. Therefore, the DRM techniques can provide indications of the general ageing condition and water content on the transformer oil-paper insulation system. Currently, it is generally believed that PDC measurements are a better tool for these dielectric response diagnostic techniques, and it has widely aroused the interest of many researchers/research groups. So far, many of the research findings in relation to PDC behavior have been commonly reported for diagnosing water content and ageing condition in transformer cellulose insulation [16-18]. However, it is somewhat difficult for power utilities to reliably and accurately predict the water content and ageing condition using the PDC technique due to the different insulation size and geometry in transformers [22-25]. Fofana et al. [22] and Hadjadj et al. [23] investigated whether the poles could be utilized for predicting the ageing condition of the whole transformer insulation. This new idea represented a major contribution because the poles are geometry independent. Unfortunately, the pole information obtained from insulation resistance (IR) and geometric capacitance (GC) measurements might be not clear due to the fact that it represents information about the whole transformer insulation but not cellulose materials in particular. In addition, the researchers did not present any quantitative relations between poles and ageing condition of whole transformer insulation. Baral et al. [24,25] assessed the water content and ageing condition of transformer main insulation systems using the poles technique. However, the water content and ageing condition in actual transformer cellulose insulation cannot be accurately obtained unless paper/pressboard specimens are taken directly from the transformer. Therefore, this new method should be further investigated under laboratory conditions. In [26] an ageing indicator, named stable depolarization charge quantity (SDCQ), to obtain DP values of transformer cellulose insulation was reported. Nevertheless, this new characteristic parameter is very geometry dependent. Therefore, it is very necessary for researchers to eliminate the geometry dependence so that the SDCQ could be utilized for field applications. The authors in [27] studied a fuzzy algorithm for assessment of transformer insulation based upon the RVM, PDC and FDS techniques. This study contributed a lot to qualitatively obtain onsite the condition of transformer cellulose insulation. In order to further promote the research area, it is also very interesting to find how to quantify the ageing condition of transformer cellulose insulation using a dielectric response technique, such as PDC measurements.

The aim of this paper is to propose a characteristic parameter for quantifying the ageing condition of transformer cellulose insulation using the PDC technique. In terms of curve fitting technique of PDC data, we obtain the branch parameters for larger time constants and investigate the ageing effect and water effect on the branch parameters of larger time constants. Although the branch parameter (resistance and capacitance) values are geometry dependent, the larger time constants are geometry independent due to the geometry independence of resistivity, vacuum dielectric permittivity and relative dielectric permittivity. A better correlation has been found between DP values and larger time constants. The preliminary feasibility of larger time constants proposed in the paper to assess ageing degree of aged pressboard specimens is reported using a laboratory case study. 


\section{Preparation of Oil-Impregnated Pressboard Specimens}

The insulation oil is the Karamay No. 25 naphthenic mineral oil, which is provided by Chongqing Chuanrun Petroleum Chemical Co., Ltd. (Chongqing, China). The typical parameters of the insulation oil specimens are as follows: density is $884.6 \mathrm{~g} / \mathrm{cm}^{3}$, kinematic viscosity is $9.652 \mathrm{~mm}^{2} / \mathrm{s}$, pour point is $<-24{ }^{\circ} \mathrm{C}$, flash point is $143{ }^{\circ} \mathrm{C}$, acidity is $<0.01 \mathrm{mg} \mathrm{KOH} / \mathrm{g}$ and breakdown voltage ( $2.5 \mathrm{~mm}$ gap electrode) is $38 \mathrm{kV}$. The transformer cellulose pressboard specimens with a high density of $1.2 \mathrm{~g} / \mathrm{cm}^{3}$ are provided by Chongqing Aea Group Transformer Co., Ltd. (Chongqing, China). These transformer cellulose pressboard discs have a thickness of $2 \mathrm{~mm}$ and diameter of $160 \mathrm{~mm}$. To prepare the oil-impregnated pressboard specimens, the insulation oil and pressboard specimens need to be pre-treated. The specific pretreatment processes are as follows:

(1) The pressboards and insulation oil are dried in a vacuum-thermal tank at $105^{\circ} \mathrm{C} / 50 \mathrm{~Pa}$ for two days.

(2) The dried and degassed insulation oil is heated to $40^{\circ} \mathrm{C} / 50 \mathrm{~Pa}$.

(3) The dried pressboards are quickly put into the dried and degassed insulation oil with vacuum impregnation for two days under the condition of $40^{\circ} \mathrm{C} / 50 \mathrm{~Pa}$.

Finally, the obtained initial moisture content in oil-impregnated pressboards is $1.11 \%$ using a Karl Fischer titration method according to IEC 60814.

\subsection{Preparation of Oil-Paper Insulation Specimens with Different Ageing Conditions}

In this report, oil-impregnated pressboard specimens with five ageing conditions are prepared. The steps of the thermal ageing experiments are as follows:

(1) The pretreated oil-impregnated pressboard specimens are divided into five equal groups. Thus these oil-impregnated pressboard specimens are put into five ageing steel cans numbered No. 1, No. 2, No. 3, No. 4 and No. 5, respectively.

(2) Appropriate copper bars are put into the steel cans, numbered No. 2-No. 5 (No. 1 is used for storing the unaged specimen). All steel cans are sealed and then treated using vacuum pumping and nitrogen charging techniques.

(3) The steel cans (No. 2-No. 5) are put into the thermal ageing oven for accelerating thermal ageing under $130{ }^{\circ} \mathrm{C}$.

(4) After ageing for 8 days (No. 2), 21 days (No. 3), 32 days (No. 4) and 42 days (No. 5), respectively, these steel cans are taken out and placed at room temperature for $48 \mathrm{~h}$. Then, the DP values of cellulose pressboard specimens are measured in order to obtain the degradation degree of aged and unaged cellulose pressboard specimens according to IEC 60450.

\subsection{Preparation of Oil-Paper Insulation Specimens with Different Water Contents}

To prepare the cellulose pressboard specimens with desired water contents $(1 \%, 2 \%, 3 \%$ and $4 \%$ ), we perform water intake experiments for cellulose pressboard specimens with the same ageing duration. The water intake activities are implemented at the following steps: during every test, three pieces of pressboards with the corresponding ageing condition are randomly sampled. We firstly clean the residual dielectric liquid on the surface layer of the cellulose pressboards to perform water intake easily. Then, the cleaned pressboard specimens are placed on a precision scale and the initial weights are recorded. The desired weights are calculated. The humidifier is opened to increase the ambient humidity. During the water intake process, the pressboard specimen weights are constantly monitored using a precision scale until the target weights are obtained. After that, the pressboard specimens are quickly placed in a three-electrode test cell and kept for two days under $45{ }^{\circ} \mathrm{C}$ to insure temperature equalization between the pressboard samples and insulation oil for the PDC measurements. After performing the PDC measurements, the pressboard specimens are sampled to determine the final water content according to IEC 60814. 


\section{Introduction of the PDC Test Platform}

\subsection{Three-Electrode Test Cell}

In order to perform the PDC measurements on oil-impregnated pressboards, a three-electrode test cell which is shown in Figure 1 was made in the lab. This apparatus includes a high voltage electrode, a measuring electrode and a guard electrode. The voltage electrode and measuring electrode have the diameters of $141 \mathrm{~mm}$ and $113 \mathrm{~mm}$, respectively. The voltage electrode is connected to an additional weight (a copper plate) to insure the close contact between pressboard and the electrodes and equalize the pressure on the pressboard. Furthermore, to ensure a better repeatability in each test, we remove the air bubbles between the electrode and the pressboard using a special bleeder hole.

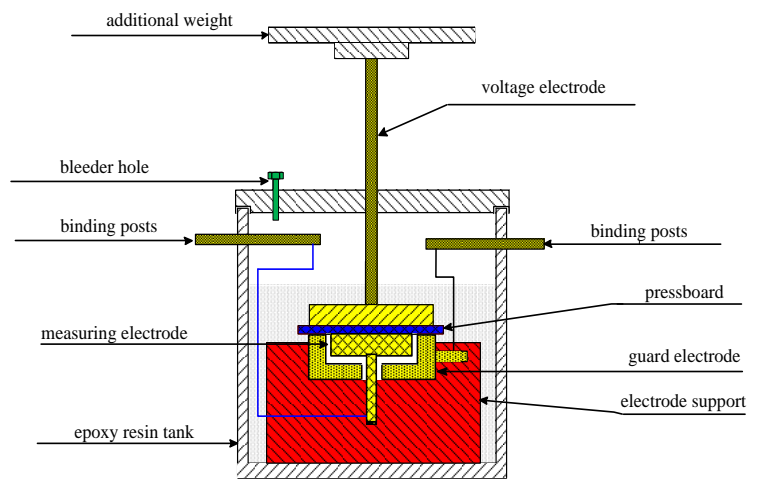

Figure 1. Schematic diagram of the three-electrode test cell.

\subsection{DIRANA}

In this paper, the PDC results are obtained using the DIRANA (Chinese version, OMICRON, Electronics $\mathrm{GmbH}$, Klaus, Austria). The testing times of polarization and depolarization current of oil impregnated pressboard specimen are both set to $5000 \mathrm{~s}$. The measuring voltage is set to $\mathrm{U}_{0}=200 \mathrm{~V}$. In order to insure the reliability of the PDC results, the pressboards are tested for three times and the average values are taken as the final PDC results.

\section{PDC Results and Analysis}

In this section, we present the PDC measurement results of oil-impregnated pressboard specimens with different ageing conditions and different water contents and also analyze the ageing effect on the PDC data in detail.

\subsection{Ageing Effect on Polarization Current}

Figure 2 shows the polarization current results of oil-impregnated pressboard specimens with different ageing times at $45^{\circ} \mathrm{C}$. It could be seen that the majority of polarization current curves moved towards the top left and the tail of the polarization current increased gradually with as the ageing time increased. The polarization current results of oil-impregnated pressboard specimens (aged for 8 days, water content $2.82 \%$ ) are abnormal. This indicated that the conductivity of the insulation oil and cellulose pressboards increased gradually as the ageing time increased. The abnormal polarization current results of oil-impregnated pressboard specimens with 8 days of ageing and water content $2.82 \%$ are due to that the water migration between the ambient air and oil-impregnated pressboard specimens during the moisture measurement process. The authors believe that the variation of polarization current curves at any ageing condition depends on two factors. The first factor is the insulation resistance. A more severe ageing condition in cellulose pressboard gives rise to a lower insulation resistance value. The decreasing insulation resistance contributes to increase the conductive current component of the polarization current results. The second factor is the polarization behavior inside cellulose pressboard. The authors 
of [18] showed that the PDC results mainly reflect the Maxwell-Wagner effect inside the cellulose pressboard when the response duration is generally $5000 \mathrm{~s}$ and above. The polarization duration in our PDC measurement is exactly set to $5000 \mathrm{~s}$, therefore we believe that the polarization current shown in Figure 2 is mainly attributed to the Maxwell-Wagner effect inside the cellulose pressboard. In addition, the scission of cellulose chains can produce a large number of ageing by-products with strong polarization, such as water, organic acids, and furans. These ageing by-products, in fact, can strengthen the electron displacement polarization. Hence, these polarization behaviors give rise to a severe increase in the relaxation component of the polarization current results.

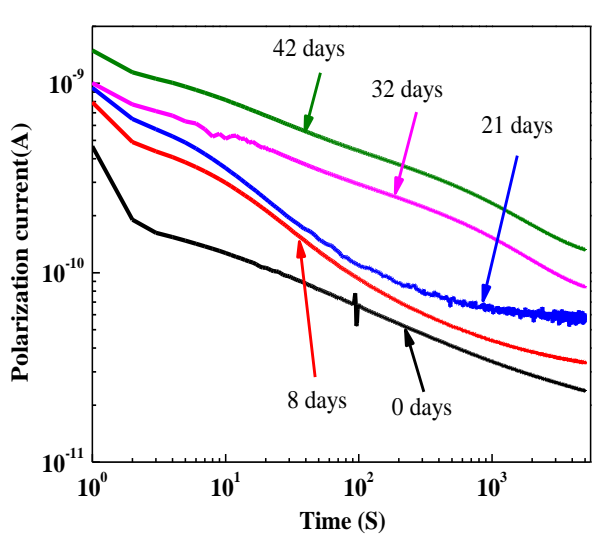

(a)

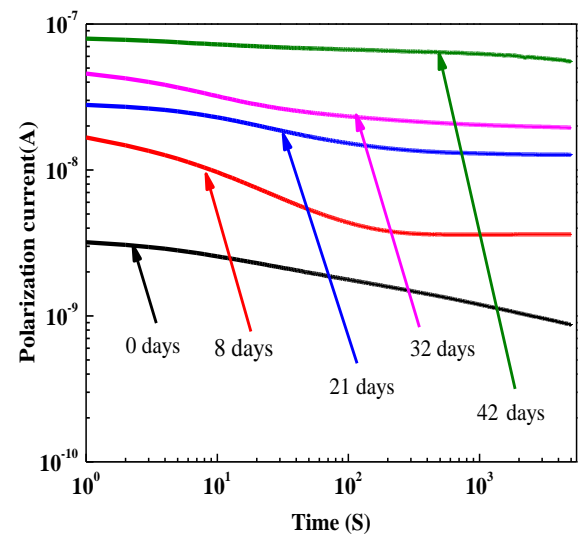

(c)

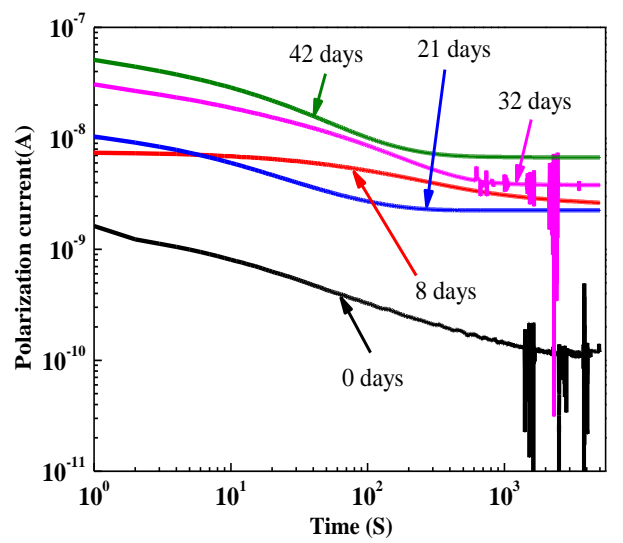

(b)

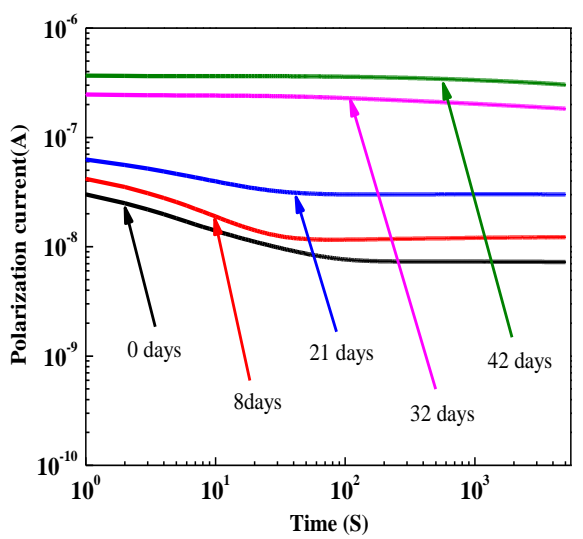

(d)

Figure 2. Polarization current results of oil-impregnated pressboards with different ageing times (a) water content $1 \%$; (b) water content $2 \%$; (c) water content $3 \%$; (d) water content $4 \%$.

\subsection{Ageing Effect on Depolarization Current}

Figure 3 shows the depolarization current results of oil-impregnated pressboard specimens with different ageing times at $45^{\circ} \mathrm{C}$. It could be seen that the depolarization current results moved to the top left overall and the tail of the depolarization current increased gradually with the increase of ageing time. In addition, we also observed the noise current at the end of depolarization current shown in Figure $3 \mathrm{a}, \mathrm{b}$. This phenomenon may be attributed to the fluctuation of the weak electric field present in our laboratory.

As for the depolarization current results shown in Figure 3, we believe the variation of depolarization current curves under any ageing condition depends on the relaxation current component due to the fact that the dc voltage is removed from the oil-impregnated pressboard. Moreover, it is observed that the tail values of depolarization currents seem to be irregular. This may be attributed to the relaxation polarization behavior of some dipoles inside the cellulose insulation which can indicate the condition of the insulation. 


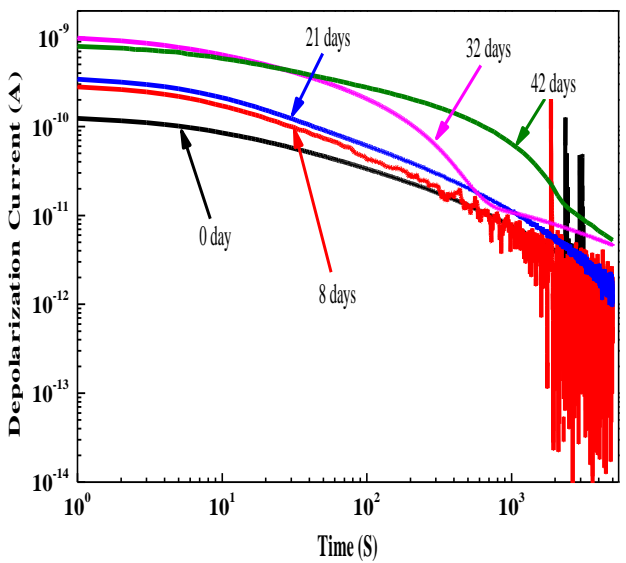

(a)

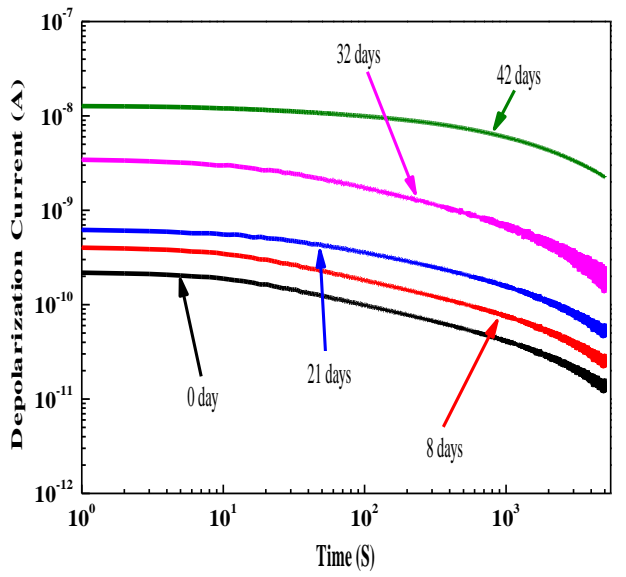

(c)

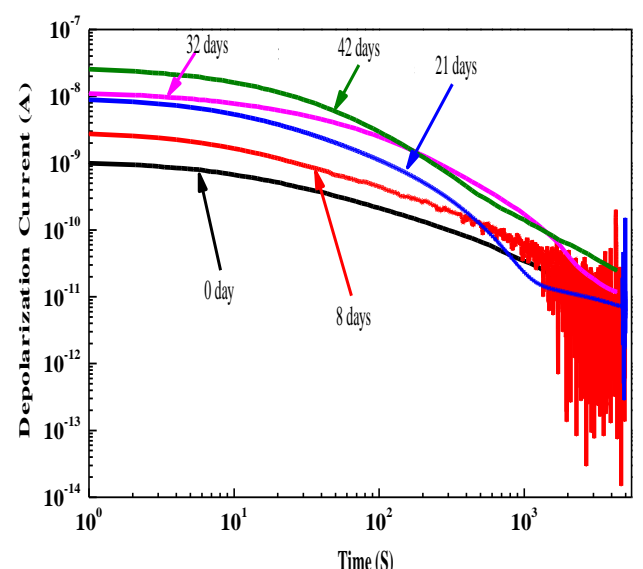

(b)

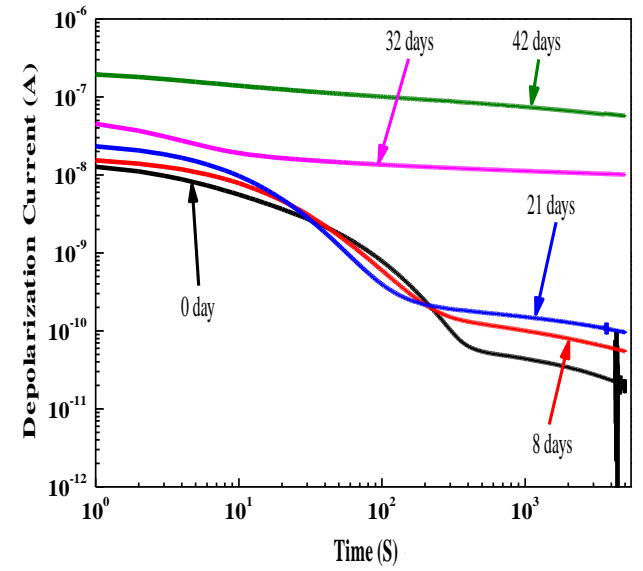

(d)

Figure 3. Depolarization current results of oil-impregnated pressboards with different ageing times. (a) water content $1 \%$; (b) water content $2 \%$; (c) water content $3 \%$; (d) water content $4 \%$.

\section{Quantifying the Ageing Condition of Transformer Cellulose Insulation Using Large Time Constant}

A typical transformer main insulation is usually composed of barriers, spacers and oil ducts. The authors of [19] provided a structural diagram of the main insulation system of a transformer with double-winding. In [28] it was pointed out that the relaxation polarization behavior of composite dielectric insulation such as transformer oil-paper insulation can be expressed using the sum of a set of index functions contained with $\mathrm{n}$ relaxation elements, which is the parallel connection of $n R-C$ series branches on the circuit. According to this theory, in [29] the authors take the transformer main insulation structure as a whole and reduce to the resistance and capacitance in the equivalent circuit to obtain the extended Debye equivalent model shown in Figure 4. The $R_{g}$ and $C_{g}$ represent the insulation resistance and geometric capacitance of the oil-paper insulation system, respectively, and $R_{i}$ and $C_{i}$ represent the resistance and capacitance of the $i(1 \leq i \leq n)$ branch. It should be pointed out that it is still a challenge for researchers about how to determine the number of $R-C$ series branches. Presently, it is found that different authors have reported different number of $R-C$ series branches. In this paper, we obtain the parameters of $R-C$ series branches using the multinomial fitting technique of PDC curves introduced in [30]. Due to space limitations, the details of the process are not presented in our paper. 


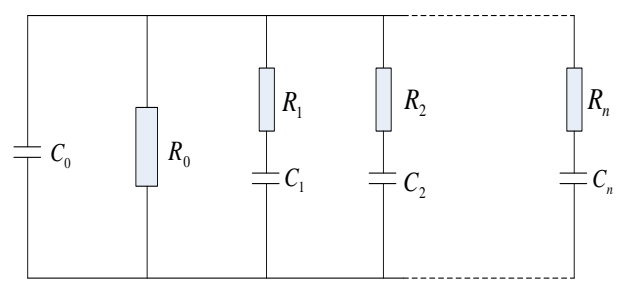

Figure 4. Extended Debye model for transformer oil-paper insulation.

Currently, how to quantize the ageing effect and water effect of cellulose insulation (especially the ageing effect) on PDC characteristics has become a research hotspot for experts and scholars. The authors in $[22,23]$ proposed a system pole technique to obtain the water content in transformer cellulose insulation. The system pole can be written as:

$$
\left\{\begin{array} { c } 
{ R _ { 0 } = \rho \frac { L } { S } } \\
{ C _ { 0 } = \varepsilon _ { 0 } \varepsilon _ { r } \frac { S } { L } }
\end{array} \Rightarrow \left\{\begin{array}{c}
P=\frac{1}{R_{0} C_{0}} \\
P=\frac{1}{\rho \varepsilon_{0} \varepsilon_{r}}
\end{array}\right.\right.
$$

In Equation (1), $P$ is the system pole, $R_{0}$ is the insulation resistance of the specimen, $C_{0}$ is the capacitance of the specimen, $S$ is its effective cross section area of the specimen, $L$ is its effective thickness of the specimen, $\rho$ is the resistivity of the specimen, $\varepsilon_{0}$ is the vacuum dielectric permittivity of the specimen, $\varepsilon_{r}$ is the relative dielectric permittivity of the specimen.

The research in $[22,23]$ has found that since the terms $\rho, \varepsilon_{0}$ and $\varepsilon_{r}$ have nothing to do with the insulation size, therefore the system pole $P$ is not affected by the size of the cellulose insulation. In addition, the authors also found that the system pole $P$ has a good correlation with the water content and ageing condition in cellulose insulation. However, the insulation resistance $R_{0}$ and the geometric capacitance $C_{0}$ only reflect the insulation condition of overall insulation, and the system pole technology might not reliably assess the water content and ageing condition in transformer cellulose insulation. Therefore, it is necessary to further research on applying the system pole technology to quantize the water content and ageing condition in transformer cellulose insulation.

\subsection{Large Time Constant Technique}

With reference to the research results in [22,23], as well as the expression of system pole in Equation (2), the time constant of extended Debye circuit model can be written as:

$$
\left\{\begin{array} { c } 
{ R _ { i } = \rho _ { i } \frac { L } { S } } \\
{ C _ { i } = \varepsilon _ { 0 } \varepsilon _ { r } ^ { i } \frac { S } { L } }
\end{array} \Rightarrow \left\{\begin{array}{c}
\tau_{i}=R_{i} C_{i} \\
\tau_{i}=\rho_{i} \varepsilon_{0} \varepsilon_{r}^{i}
\end{array}(i=1,2, \cdots n)\right.\right.
$$

In Equation (2), the term $i$ represents the number of dipole groups with different types, the $n$ is the number of dipole groups, normally $n<10$, the $\tau_{i}$ is the time constant of the $i$ branch, which reflects the relaxation polarization behaviors of different dipole groups, the $R_{i}$ is the resistance of the $i$ branch, the $C_{i}$ is the capacitance of the $i$ branch, the $S$ is the effective cross section area of the specimen, $L$ is the effective thickness of the specimen, the $\rho_{i}$ is the resistivity of the $i$ dipole group, the $\varepsilon_{0}$ is the vacuum dielectric permittivity, the $\varepsilon_{r}{ }^{i}$ is the relative dielectric permittivity of the $i$ dipole group. The $\varepsilon_{0}$, $\rho_{i}$ and $\varepsilon_{r}{ }^{i}$ have nothing to do with the insulation size of the cellulose pressboard specimen. Therefore, the time constant $\tau_{i}=R_{i} C_{i}$ in an extended Debye circuit model has nothing to do with the insulation size of the cellulose pressboard specimen.

Studies in $[29,30]$ have shown that the initial measurement part of PDC results can be fitted by the small time constant of extended Debye model while the final measurement results of PDC results can be fitted by the large time constant of an extended Debye model. Therefore, we adopt the maximum 
time constant $\left(\tau_{\max 1}\right)$ and the second maximum time constant $\left(\tau_{\max 2}\right)$ of the extended Debye model to attempt to assess the ageing condition of transformer cellulose insulation. The large time constants ( $\tau_{\max 1}$ and $\tau_{\max 2}$ ) can be written as:

$$
\left\{\begin{array}{l}
\tau_{\max 1}=R_{\max 1} C_{\max 1}=\rho_{\max 1} \varepsilon_{0} \varepsilon_{r}^{\max 1} \\
\tau_{\max 2}=R_{\max 2} C_{\max 2}=\rho_{\max 2} \varepsilon_{0} \varepsilon_{r}^{\max 2}
\end{array}\right.
$$

\subsection{Ageing Effect on Resistances, Capacitances and Large Time Constant of Maximum and Second Maximum} $R-C$ Branches

The computation results of resistances $\left(R_{\max 1}\right.$ and $\left.R_{\max 2}\right)$ and capacitances $\left(C_{\max 1}\right.$ and $\left.C_{\max 2}\right)$ of maximum and second maximum $R-C$ branches are shown in Figure 5. As can be seen, under the same water content levels, the values of $R_{\max 1}, R_{\max 2}, C_{\max 1}$ and $C_{\max 2}$ changed with an increase in ageing time. The $R_{\max 1}$ and $R_{\max 2}$ values decreased, but there was a little fluctuation, while $C_{\max 1}$ and $C_{\max 2}$ presented a contrary tendency, which is an indication of a stronger polarization behavior attributed to the ageing by-products such as water, organic acid, and furan inside the cellulose insulation. The resistances and capacitances provide valuable information about the condition of the insulation. A bad condition (such as ageing) of the cellulose pressboard tends to decrease the value of $R_{\max 1}$ and $R_{\max 2}$ and increase the value of $C_{\max 1}$ and $C_{\max 2}$ thus increasing the magnitudes of relaxation current at the end of time. This change in resistance and capacitances also indicates permanent degradation of the cellulose insulation. In addition, we observe the phenomenon that the rate of change of $C_{\max 1}$ and $C_{\max 2}$ is somewhat higher than $R_{\max 1}$ and $R_{\max 2}$, and it is indicate that the result of multiplication between resistances and capacitances (the larger time constant described later in this paper) is determined by $C_{\max 1}$ and $C_{\max 2}$. In [26,29] the authors reached the opposite conclusion that the rate of change of $R_{\max 1}$ and $R_{\max 2}$ is somewhat higher than that of $C_{\max 1}$ and $C_{\max 2}$. This might due to the fact that a larger time constant is assumed to be a constant value.

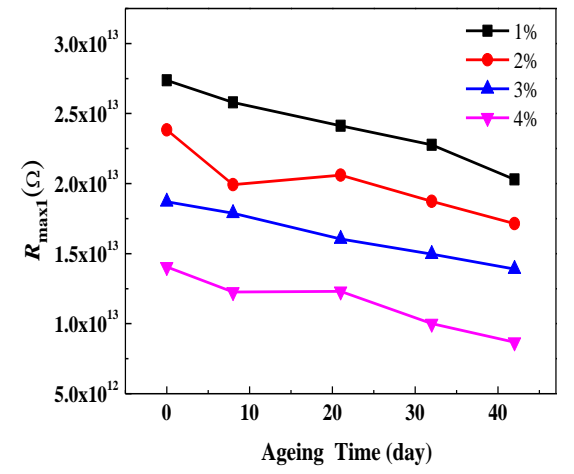

(a)

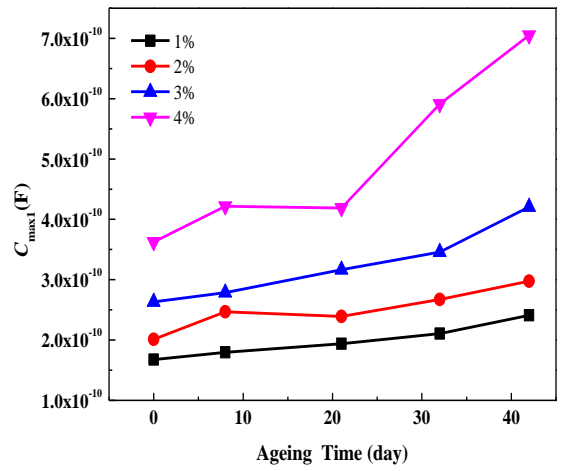

(c)

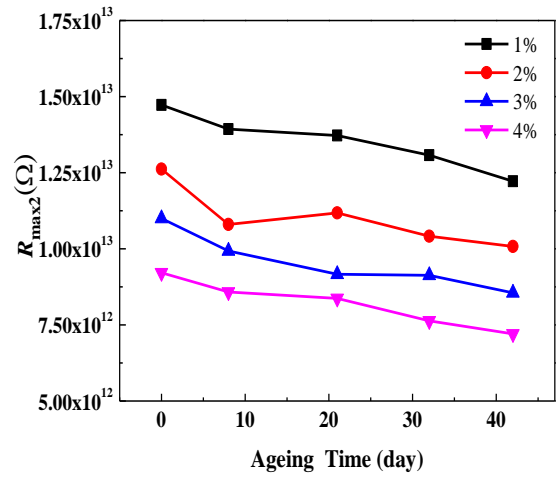

(b)

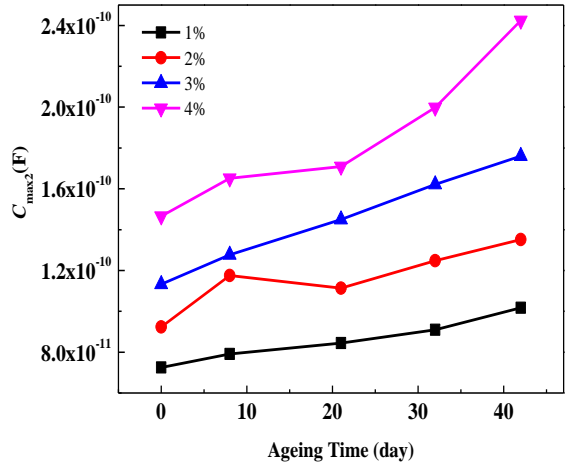

(d)

Figure 5. Resistances and capacitances of maximum and second maximum $R-C$ branches with different times. (a) $R_{\max 1}$; (b) $R_{\max 2}$; (c) $C_{\max 1}$; (d) $C_{\max 2}$. 
Figure 6 shows the variations of the maximum time constant $\left(\tau_{\max 1}\right)$ and second maximum time constant $\left(\tau_{\max 2}\right)$. It could be found that the $\tau_{\max 1}$ and $\tau_{\max 2}$ increase with ageing duration increase, but there is a little fluctuation. According to the theoretical knowledge of the circuit principle, the time constant characterizes the attenuation speed of the capacitive current of an $R-C$ circuit.

The calculation results of the above time constant show that the cellulose pressboard in poor insulation conditions will increase the value of the large time constant, and then increase the amplitude at the end of PDC curves. In addition, on the contrary, the pressboard in good insulation conditions will decrease the large time constant, thus contributing to decrease the amplitude at the end of PDC curves.

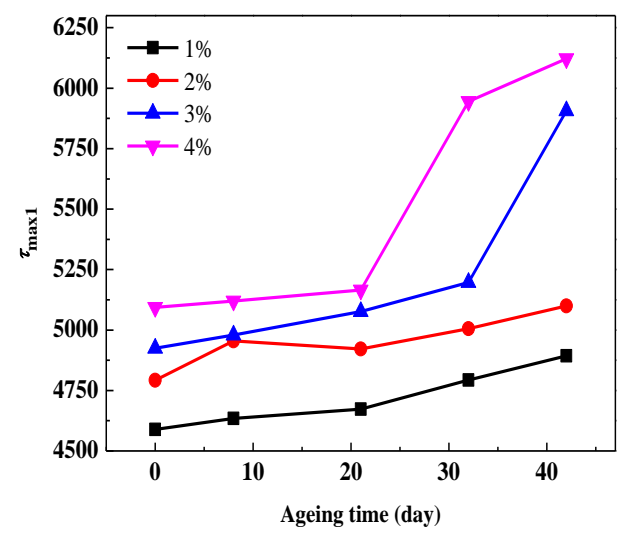

(a)

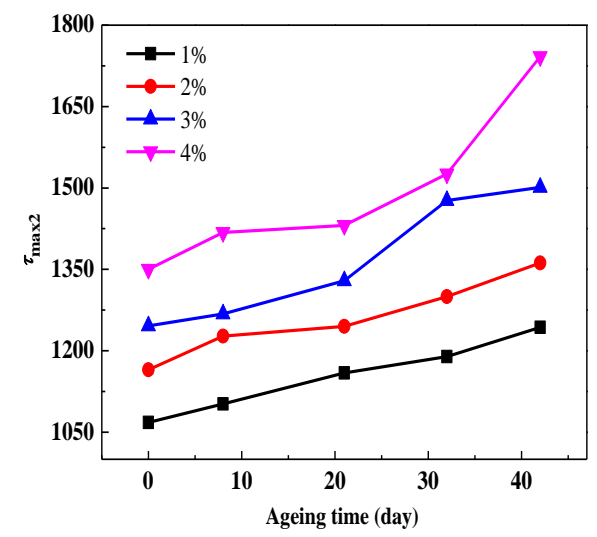

(b)

Figure 6. Maximum and second maximum time constants with different ageing times. (a) $\tau_{\max 1}$; (b) $\tau_{\max 2}$.

\subsection{Quantitative Relationship between Large Time Constant and DP Value}

Figure 7 presents the fitting relations between larger time constants and DP values (the real line is the computation curve while the dotted line is the fitted curve). It is found that for the tested pressboard specimens at the same water gradients, the $\tau_{\max 1}$ and $\tau_{\max 2}$ gradually increase as the DP values decrease.

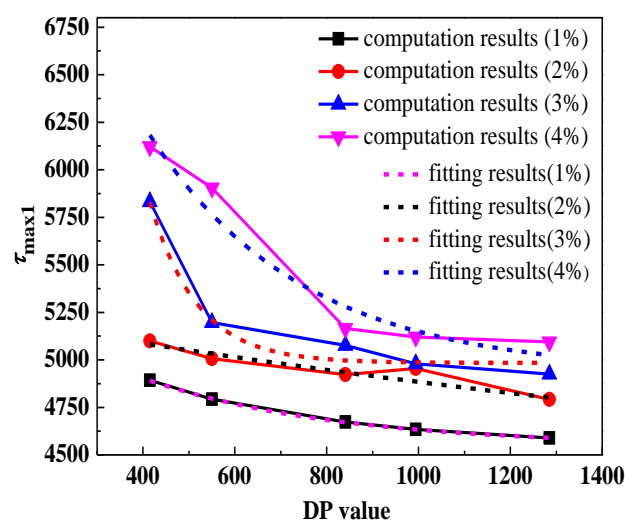

(a)

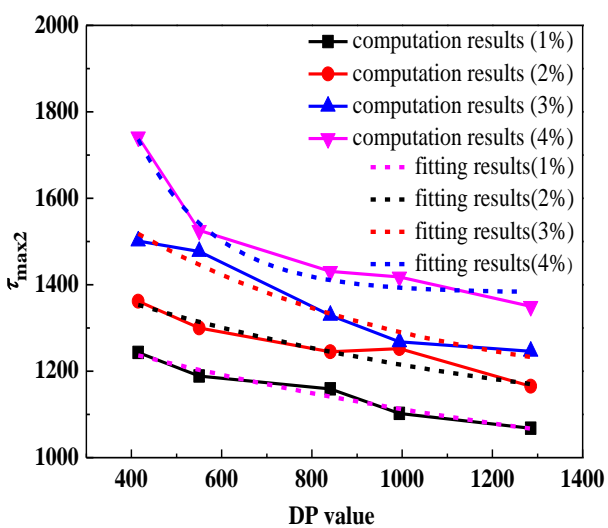

(b)

Figure 7. Relations between larger time constants and DP values. (a) Relations between $\tau_{\max 1}$ and DP values (b) Relations between $\tau_{\max 2}$ and DP values.

In addition, according to the fitting relationship between larger time constants and DP values shown in Tables 1 and 2, good exponential relationships between $\tau_{\max 1} / \tau_{\max 2}$ and DP values are observed overall except for the cellulose pressboard specimens with the desired water content of $2 \%$ (the $R$-squared value is only 0.80 ). The $R$-squared values of the remaining three exponential relations are all over 0.92 . 
Table 1. Fitting relations between the maximum time constants and DP values.

\begin{tabular}{ccc}
\hline Water & Fitting Equation $\boldsymbol{\tau}_{\max 1}=\mathbf{A}+\mathbf{B} \times \exp (\mathbf{C} \times \mathbf{D P})$ & $\mathbf{R}^{\mathbf{2}}$ \\
\hline $1 \%$ & $\tau_{\max 1}=4548.317+932.157 \exp (-0.0024 \times \mathrm{DP})$ & 0.99 \\
$2 \%$ & $\tau_{\max 1}=-33049.599+38257.396 \exp (-8.0977 \times \mathrm{DP})$ & 0.80 \\
$3 \%$ & $\tau_{\max 1}=4984.090+48336.764 \exp (-0.0098 \times \mathrm{DP})$ & 0.96 \\
$4 \%$ & $\tau_{\max 1}=4934.992+4360.154 \exp (-0.0030 \times \mathrm{DP})$ & 0.91 \\
\hline
\end{tabular}

Table 2. Fitting relations between the second maximum time constants and DP values.

\begin{tabular}{ccc}
\hline Water & Fitting Equation $\boldsymbol{\tau}_{\max 1}=\mathbf{A}+\mathbf{B} \times \exp (\mathbf{C} \times \mathbf{D P})$ & $\mathbf{R}^{\mathbf{2}}$ \\
\hline $1 \%$ & $\tau_{\max 2}=852.655+506.382 \exp (-0.0007 \times \mathrm{DP})$ & 0.92 \\
$2 \%$ & $\tau_{\max 2}=1028.678+482.556 \exp (-0.0010 \times \mathrm{DP})$ & 0.96 \\
$3 \%$ & $\tau_{\max 2}=1126.325+728.836 \exp (-0.0015 \times \mathrm{DP})$ & 0.93 \\
$4 \%$ & $\tau_{\max 2}=1381.403+4040.509 \exp (-0.0059 \times \mathrm{DP})$ & 0.95 \\
\hline
\end{tabular}

\subsection{Case Verification}

In order to verify the feasibility of the fitting relations presented in Tables 1 and 2, it would be interesting to estimate the condition of aged pressboard specimens. In this part, we take two

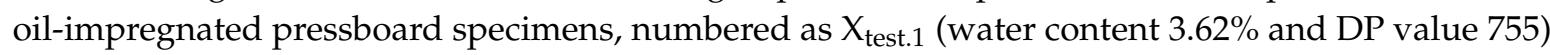

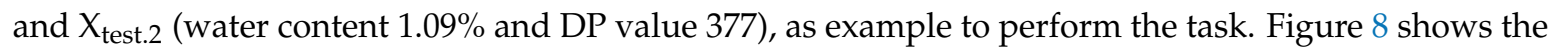
PDC results of $X_{\text {test.1 }}$ and $X_{\text {test.2. }}$ According to the fitting relations presented in Tables 1 and 2, and the $\tau_{\max 1}$ and $\tau_{\max 2}$ obtained from extended Debye model based upon the PDC results of $X_{\text {test.1 }}$ and $X_{\text {test.2, }}$ the computation results of DP values on $X_{\text {test. } 1}$ are equal to 806 and 815 respectively, and the actual

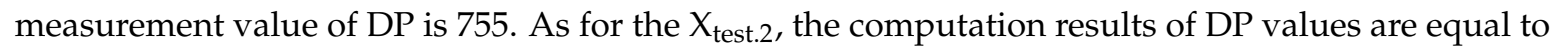
429 and 458, respectively, and the actual measurement value of DP is 377 . The computation values are in accordance with actual measurement values. The differences might derive from the errors of both the experimental data and computation data, and the errors results are acceptable.

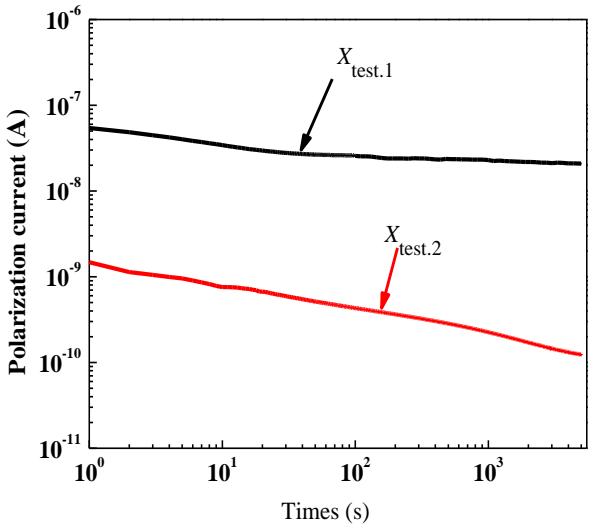

(a)

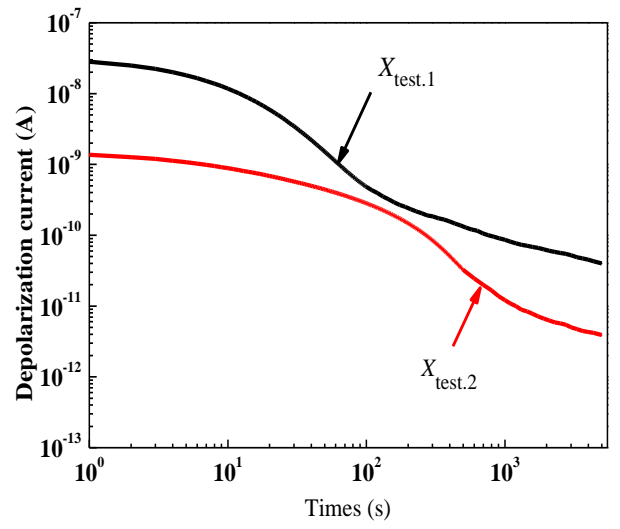

(b)

Figure 8. PDC results of the test samples. (a) $X_{\text {test.1 }}(\mathbf{b}) X_{\text {test.2. }}$.

\section{Water Effect on PDC Results and Branch Parameters Obtained from the Extended Debye Model}

According to the PDC results shown in Figures 2 and 3, this section redraws the PDC results of the oil-impregnated pressboard specimens at $45^{\circ} \mathrm{C}$ to study the water effect on the PDC results and branch parameters obtained from the extended Debye model. 


\subsection{Water Effect on Polarization Current}

Figure 9 shows the polarization current results of oil-impregnated pressboard specimens with different water contents at $45^{\circ} \mathrm{C}$. It is observed that the water content has a very significant effect on the polarization current values. The polarization current values increased significantly and moved upward overall as the water content increased.

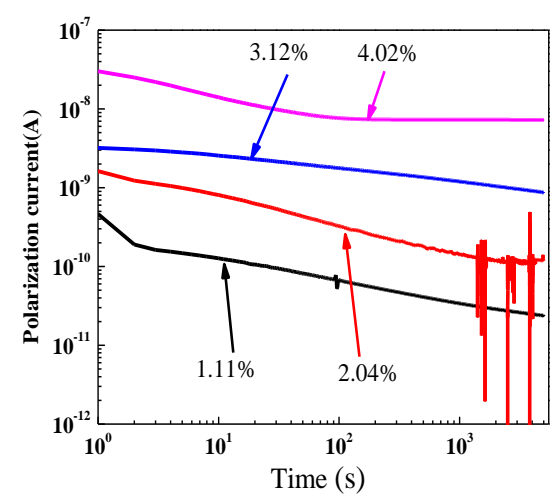

(a)

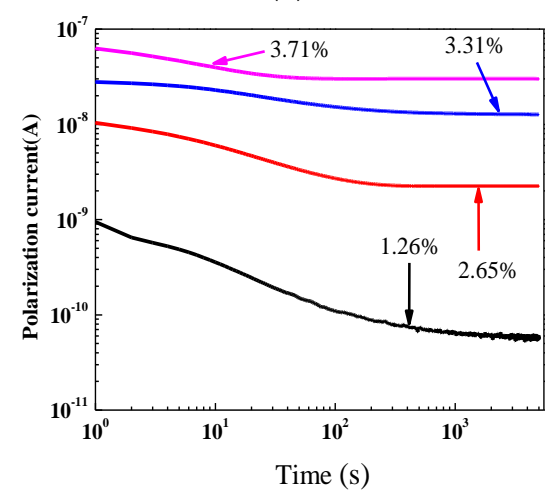

(c)

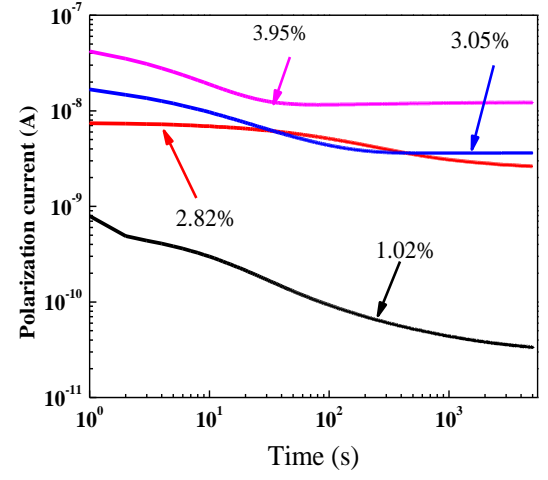

(b)

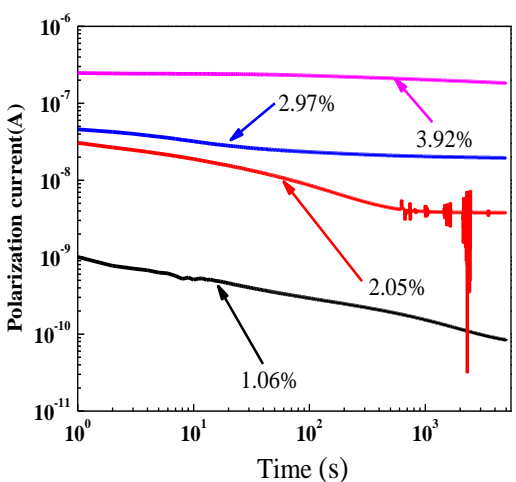

(d)

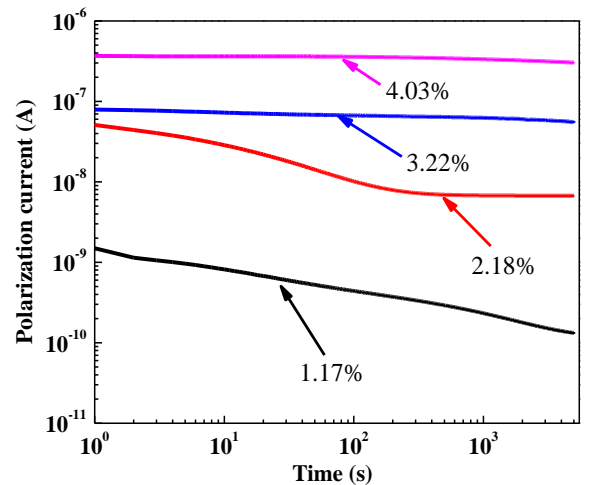

(e)

Figure 9. Polarization current results of oil-impregnated pressboards with different water contents. (a) Ageing for 0 day; (b) Ageing for 8 days; (c) Ageing for 21 days; (d) Ageing for 32 days; (e) Ageing for 42 days.

Compared with insulation ageing, the water effect on the polarization current results is more obvious. In addition, it is found that the stable value of the polarization current also increased significantly as the water content increased. Studies in $[29,30]$ have reported that the oil conductivity is related to the initial measuring part of polarization current, while the paper (pressboard) conductivity is related to the final measuring part of polarization current. Therefore, the conductivity both oil and paper (pressboard) increases as the water content increases. This is in accordance with the literature $[17,29,31]$. 


\subsection{Water Effect on Depolarization Current}

Figure 10 shows the depolarization current results of oil-impregnated pressboard specimens with different water contents at $45^{\circ} \mathrm{C}$. It could be seen that the depolarization current values increased significantly and moved upward overall with the increase of water content inside the cellulose pressboard specimens. Moreover, as for the depolarization current results shown in Figure 10, we believe that the variation of depolarization current curves at any moisture contents only depends on the depolarization behaviors of the transformer cellulose insulation due to the fact that the $\mathrm{dc}$ voltage is removed from the oil-impregnated pressboard specimen. A higher moisture contents in cellulose pressboard gives also rise to a strengthening of the electron displacement polarization, and the Maxwell-Wagner effect inside the cellulose pressboard specimens.

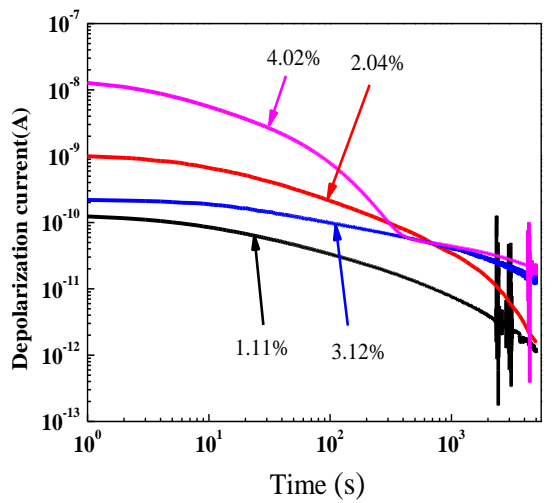

(a)

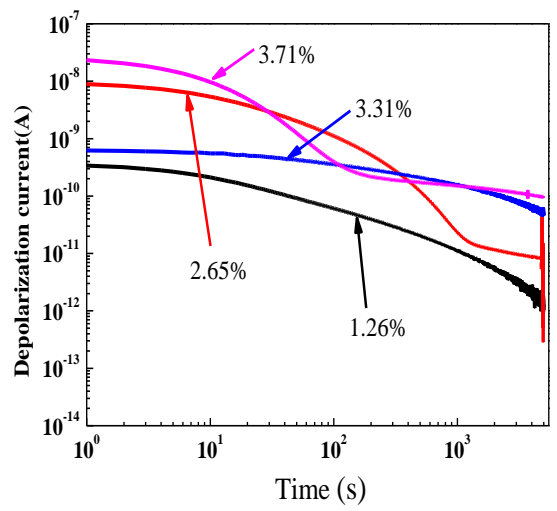

(c)

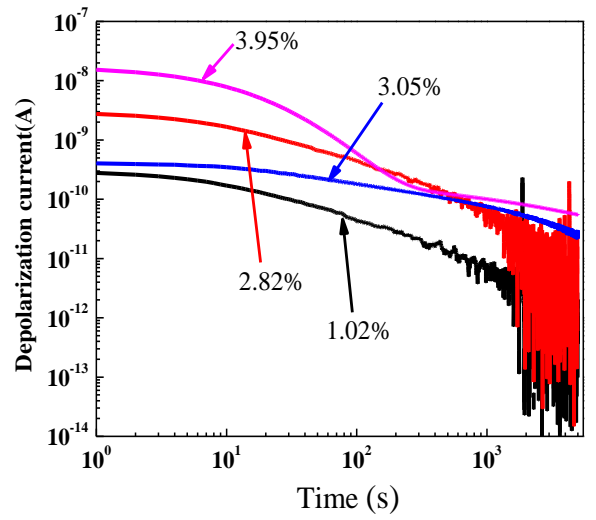

(b)

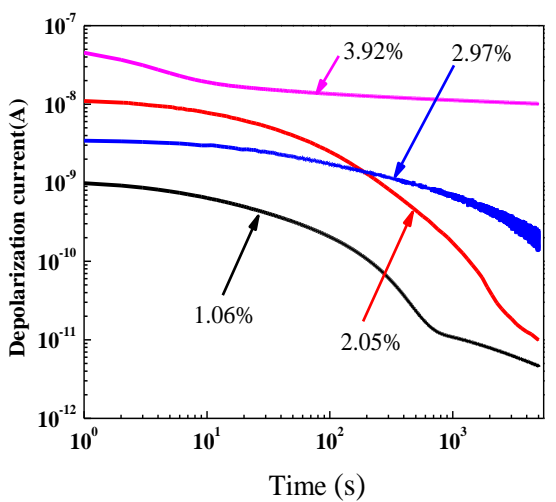

(d)

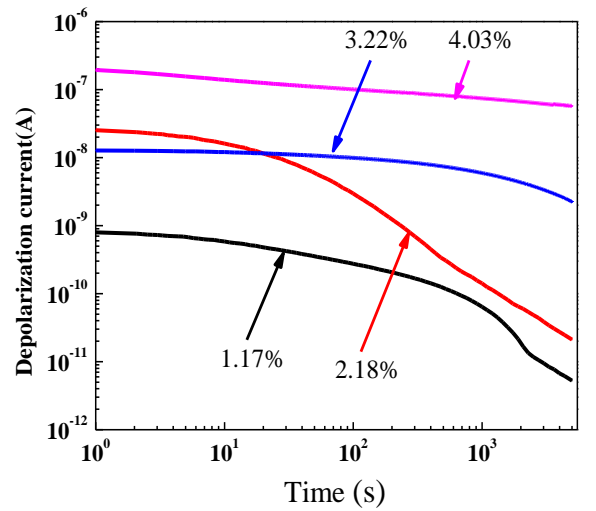

(e)

Figure 10. Depolarization current results of oil-impregnated pressboards with different water contents. (a) Ageing for 0 day; (b) Ageing for 8 days; (c) Ageing for 21 days; (d) Ageing for 32 days; (e) Ageing for 42 days. 
Therefore, the amplitude of depolarization current values shows an increasing trend and the attenuation speed of the depolarization current curve slows down somewhat. In addition, with regard to the depolarization current results, in our experiment, the water effect on depolarization current results is found to be more predominant than the ageing effect.

\subsection{Water Effect on Resistances, Capacitances and Large Time Constant of Maximum and Second Maximum R-C Branches}

Figure 11 presents the computation results of resistances $\left(R_{\max 1}\right.$ and $\left.R_{\max 2}\right)$ and capacitances $\left(C_{\max 1}\right.$ and $\left.C_{\max 2}\right)$ with different water contents. It is found that the $R_{\max 1}, R_{\max 2}, C_{\max 1}$ and $C_{\max 2}$ have changed obviously due to the water content increase. At higher water contents, the $R_{\max 1}$ and $R_{\max 2}$ values have decreased while the $C_{\max 1}$ and $C_{\max 2}$ presented a contrary tendency, which is an indication of both stronger conduction and polarization inside the cellulose insulation. A higher level of water content in cellulose pressboard can strengthen the conduction currents due to the increased magnitude of charge carriers such as hydrophilic particles or hydrophilic groups. This may contribute to decrease $R_{\max 1}$ and $R_{\max 2}$ values. In addition, the increased water molecules are deemed to polar substance, which could strengthen the electron displacement polarization and Maxwell-Wagner inside the cellulose pressboard specimens, and thus further leads to decrease $R_{\max 1}$ and $R_{\max 2}$ values. Furthermore, the higher the water content inside cellulose insulation is, the more the energy inside dipoles stores. This may contribute to increase $C_{\max 1}$ and $C_{\max 2}$ values. It is noteworthy that, in contrast to ageing effect, this change values in resistance and capacitance does not indicate permanent degradation of the cellulose insulation, due to the water effect is inverted when water content in cellulose insulation decreased. In addition, we can still observe the phenomenon that the rate of change of values of $C_{\max 1}$ and $C_{\max 2}$ is higher than the values of $R_{\max 1}$ and $R_{\max 2}$. Authors in [21,24] found the opposite conclusion that the rate of change of $R_{\max 1}$ and $R_{\max 2}$ is somewhat higher than $C_{\max 1}$ and $C_{\max 2}$. This might, also, due to that larger time constant is assumed to be constant value.

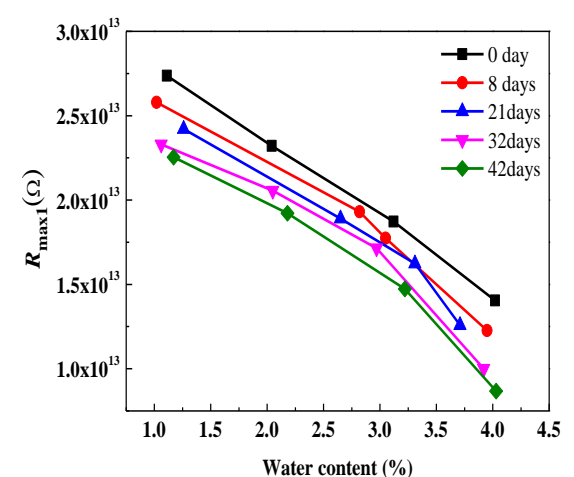

(a)

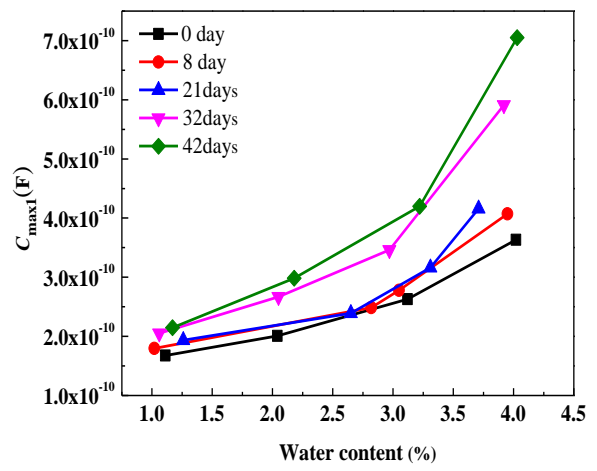

(c)

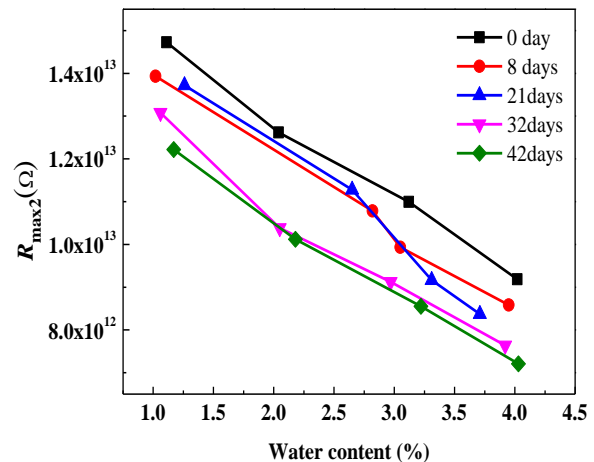

(b)

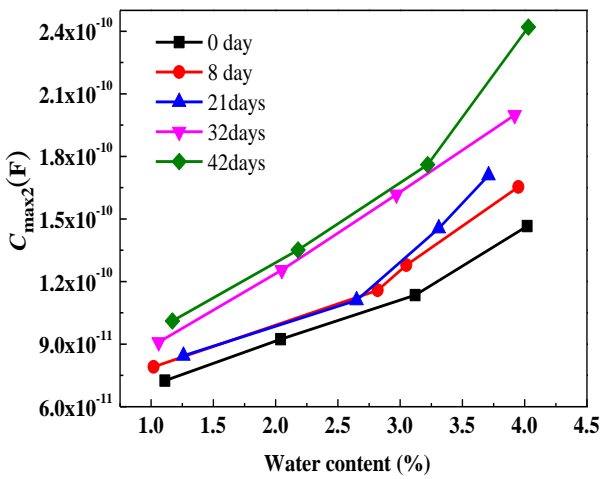

(d)

Figure 11. Resistances and capacitances of maximum and second maximum $R$ - $C$ branches with different water contents. (a) $R_{\max 1}$; (b) $R_{\max 2}$; (c) $C_{\max 1}$; (d) $C_{\max 2}$. 
Figure 12 shows the computation results of larger time constants obtained from maximum and second maximum $R-C$ branches with different water contents. It could be seen that with the water content increase the large time constant gradually increases but there is also a little fluctuation. Compared with insulation ageing, water content has a predominant effect on larger time constants due to that the amount of the ageing products such as organic acids, furan compounds and other polar matter is far less than water.

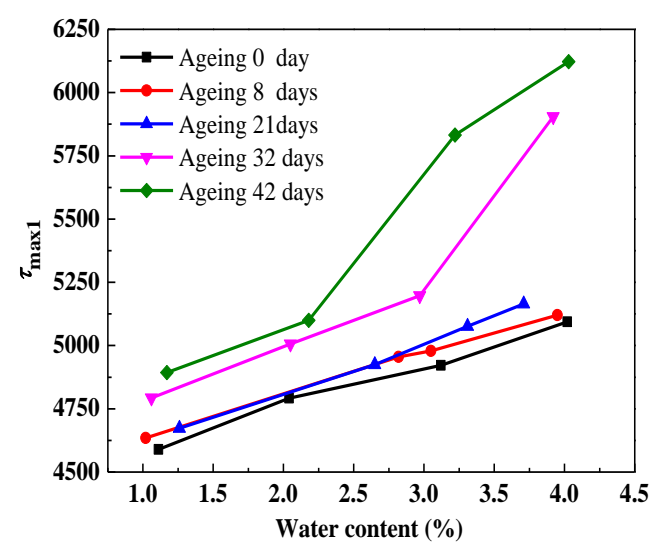

(a)

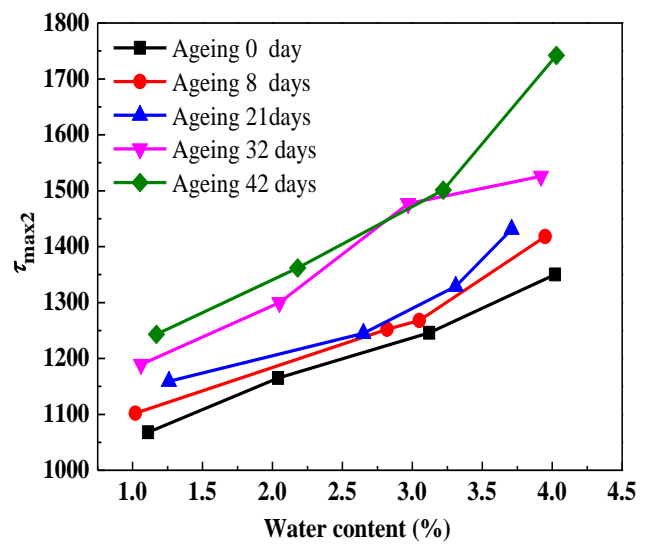

(b)

Figure 12. Maximum and second maximum time constants with different water contents. (a) $\tau_{\max 1}$; (b) $\tau_{\max 2}$.

\section{Conclusions}

This paper reports the quantitative correlations between ageing condition of transformer cellulose insulation and large time constant derived from an Extended Debye model. The detailed conclusions in this paper are as follows:

(1) The water effect on resistance values and capacitance values of maximum and second maximum $R-C$ branches is more predominant than the ageing effect. However, in contrast to the ageing effect, this change of resistance and capacitance values does not indicate permanent degradation of the cellulose insulation due to the fact the water effect is inverted when the water content decreases.

(2) The large time constants obtained from the maximum and second maximum $R-C$ branches are geometry independent. It has been observed that the large time constants show a total trend of increase but there is a little fluctuation as the DP values decrease due to the fact that the rate of change of $C_{\max 1}$ and $C_{\max 2}$ values is higher than that of the $R_{\max 1}$ and $R_{\max 2}$ values. It also has been shown that there is a good exponential relationship between large time constants and DP values.

(3) The large time constants obtained from maximum and second maximum $R-C$ branches show a total trend of increase with the water content increase but there is a little fluctuation due to the fact that the rate of change of $C_{\max 1}$ and $C_{\max 2}$ values is higher than that of the $R_{\max 1}$ and $R_{\max 2}$ values.

Acknowledgments: The authors acknowledge the National Basic Research Program of China (973 Program, 2013CB228205), and the National High-tech R \& D Program of China (863 Program, 2015AA050204), the Natural Science Foundation of Guangxi (2015GXNSFBA139235), the Foundation of Guangxi Science and Technology Department (AE020069), and the Foundation of Guangxi Education Department (T3020097903), and the National Key Research and Development Program of China (2016YFB0900101) and National Demonstration Center for Experimental Electrical Engineering Education (Guangxi University) in support of this work.

Author Contributions: In this research activity, all the authors were involved in the data collection and preprocessing phase, model constructing, empirical research, results analysis and discussion, and manuscript preparation. All authors have approved the submitted manuscript.

Conflicts of Interest: The authors declare no conflict of interest. 


\section{References}

1. Liao, R.; Zheng, H.; Grzybowski, S.; Yang, L.; Tang, C.; Zhang, Y. Fuzzy information granulated particle swarm optimisation-support vector machine regression for the trend forecasting of dissolved gases in oil-filled transformers. IET Electr. Power Appl. 2011, 5, 230-237. [CrossRef]

2. Koch, M.; Prevost, T. Analysis of dielectric response measurements for condition assessment of oil-paper transformer insulation. IEEE Trans. Dielectr. Electr. Insul. 2012, 19, 1908-1915. [CrossRef]

3. Muthann, K.T.; Sarka, A.; Da, K.; Waldner, K. Transformer insulation life assessment. IEEE Trans. Power Deliv. 2006, 21, 150-156. [CrossRef]

4. Wang, M.; Vandermaar, A.J.; Srivastava, K.D. Review of condition assessment of power transformers in service. IEEE Electr. Insul. Mag. 2002, 18, 12-15. [CrossRef]

5. Liao, R.; Liang, S.; Sun, C.; Yang, L.; Sun, H. A comparative study of thermal aging of transformer insulation paper impregnated in natural ester and in mineral oil. Eur. Trans. Electr. Power 2010, 20, 518-533. [CrossRef]

6. Tenbohlen, S.; Coenen, S.; Djamali, M.; Müller, A.; Samimi, M.H.; Siegel, M. Diagnostic measurements for power transformers. Energies 2016, 9, 347. [CrossRef]

7. Godina, R.; Rodrigues, E.M.G.; Matias, J.C.O.; Catalão, J.P.S. Effect of loads and other key factors on oil-transformer ageing: Sustainability benefits and challenges. Energies 2015, 8, 12147-12186. [CrossRef]

8. Lee, B.E.; Park, J.W.; Crossley, P.A.; Kang, Y.C. Induced voltages ratio-based algorithm for fault detection, and faulted phase and winding identification of a three-winding power transformer. Energies 2014, 7, 6031-6049. [CrossRef]

9. Wang, C.; Wu, J.; Wang, J.; Zhao, W. Reliability analysis and overload capability assessment of oil-immersed power transformers. Energies 2016, 9, 43. [CrossRef]

10. Prasojo, A.; Diwyacitta, K.; Gumilang, H. Transformer paper expected life estimation using ANFIS based on oil characteristics and dissolved gases (case study: Indonesian transformers). Energies 2017, 10, 1135. [CrossRef]

11. Saha, T.K. Review of modern diagnostic techniques for assessing insulation condition in aged transformers. IEEE Trans. Dielectr. Electr. Insul. 2003, 10, 903-917. [CrossRef]

12. Linhjell, D.; Lundgaard, L.E.; Gafvert, U. Dielectric response of mineral oil impregnated cellulose and the impact of aging. IEEE Trans. Dielectr. Electr. Insul. 2007, 14, 156-169. [CrossRef]

13. Liao, R.; Hao, J.; Chen, G.; Yang, L. Quantitative analysis of ageing condition of oil-Paper insulation by frequency domain spectroscopy. IEEE Trans. Dielectr. Electr. Insul. 2012, 19, 821-830. [CrossRef]

14. Saha, T.K.; Purkait, P. Investigations of temperature effects on the dielectric response measurements of transformer oil-paper insulation system. IEEE Trans. Power Deliv. 2008, 23, 252-260. [CrossRef]

15. Saha, T.K.; Zheng, T.Y. Experience with return voltage measurements for assessing insulation conditions in service-aged transformers. IEEE Trans. Power Deliv. 2003, 18, 128-135. [CrossRef]

16. We, J.; Zhang, G.; Xu, H.; Peng, H.; Wang, S.; Dong, M. Novel characteristic parameters for oil-paper insulation assessment from differential time-domain spectroscopy based on polarization and depolarization current measurement. IEEE Trans. Dielectr. Electr. Insul. 2011, 18, 1918-1928. [CrossRef]

17. Saha, T.K.; Purkait, P. Investigation of polarization and depolarization current measurements for the assessment of oil-paper insulation of aged transformers. IEEE Trans. Dielectr. Electr. Insul. 2004, 11, 144-154. [CrossRef]

18. Zaengl, W.S. Dielectric spectroscopy in time and frequency domain for HV power equipment, Part I: Theoretical considerations. IEEE Electr. Insul. Mag. 2003, 19, 9-22. [CrossRef]

19. Liao, R.; Liu, J.; Yang, L.; Gao, J.; Zhang, Y.; Lv, Y.; Zheng, H. Understanding and analysis on frequency dielectric parameter for quantitative diagnosis of water content in paper-oil insulation system. IET Electr. Power Appl. 2015, 9, 213-222. [CrossRef]

20. Wang, D.; Zhou, L.; Chen, X.; Jiang, J.; Wang, L. Modelling the low-frequency dielectric response test of insulation oil. IET Electr. Power Appl. 2017, 11, 323-330. [CrossRef]

21. Farahani, M.; Borsi, H.; Gockenbach, E. Dielectric response studies on insulating system of high voltage rotating machines. IEEE Trans. Dielectr. Electr. Insul. 2006, 13, 383-393. [CrossRef]

22. Hadjadj, Y.; Meghnefi, F.; Fofana, I.; Ezzaidi, H. On the feasibility of using poles computed from frequency domain spectroscopy to assess oil impregnated paper insulation conditions. Energies 2013, 6, 2204-2220. [CrossRef] 
23. Fofana, I.; Hemmatjou, H.; Meghnefi, F.; Farzaneh, M.; Setayeshmehr, A.; Borsi, H.; Gockenbach, E. On the frequency domain dielectric response of oil-paper insulation at low Temperatures. IEEE Trans. Dielectr. Electr. Insul. 2010, 17, 799-807. [CrossRef]

24. Baral, A.; Chakravorti, S. Assessment of non-uniform aging of cellulose dielectric using system Poles of a modified extended Debye model for oil-paper insulation of transformers. IEEE Trans. Dielectr. Electr. Insul. 2013, 20, 1922-1933. [CrossRef]

25. Baral, A.; Chakravorti, S. Prediction of water present in cellulosic part of power transformer insulation using transfer function of modified extended Debye model. IEEE Trans. Dielectr. Electr. Insul. 2014, 21, 1368-1375. [CrossRef]

26. Hao, J.; Liao, R.; Chen, G.; Ma, Z.; Yang, L. Quantitative analysis ageing condition of natural ester-paper insulation and mineral oil-paper insulation by polarization/depolarization current. IEEE Trans. Dielectr. Electr. Insul. 2012, 19, 188-199.

27. Liu, J.; Zheng, H.; Zhang, Y.; Wei, H.; Liao, R. Grey relational analysis for insulation condition assessment of power transformers based upon conventional dielectric response measurement. Energies 2017, 10, 1526. [CrossRef]

28. Jonscher, A.K. Dielectric Relaxation in Celluloses; Chelsea Dielectrics Press: London, UK, 1983.

29. Saha, T.K.; Purkait, P.; Müller, F. Deriving an equivalent circuit of transformers insulation for understanding the dielectric response measurements. IEEE Trans. Power Deliv. 2005, 20, 149-157. [CrossRef]

30. Liu, J.; Liao, R.; Zhang, Y.; Gong, C.; Wang, C.; Gao, J. Condition evaluation for aging state of transformer oil-paper insulation based on time-frequency domain dielectric characteristics. Electr. Power Compon. Syst. 2015, 43, 759-769. [CrossRef]

31. Fofana, I.; Hemmatjoua, H.; Farzaneh, M. Low temperature and water effects on polarization and depolarization currents of oil-paper insulation. Electr. Power Compon. Syst. 2010, 80, 91-97. [CrossRef]

(C) 2017 by the authors. Licensee MDPI, Basel, Switzerland. This article is an open access article distributed under the terms and conditions of the Creative Commons Attribution (CC BY) license (http:/ / creativecommons.org/licenses/by/4.0/). 